\title{
Environmentally Friendly Plating Pretreatment for ABS Plastic Using Electrolyzed Sulfuric Acid
}

\author{
Y. Nakabayashi ${ }^{1,2^{*}}$, Y. Umeda ${ }^{2,3}$, T. Nagai ${ }^{4}$, K. Tashiro ${ }^{2,3}$, H. Honma ${ }^{2}$ and H. Kouzai ${ }^{2,5}$ \\ 1 Graduate School of Engineering, Kanto Gakuin University, Yokohama Kanagawa 236-8501, Japan \\ 2 Materials and Surface Engineering Research Institute, Kanto Gakuin University, Odawara Kanagawa 250-0042, Japan \\ 3 Kanto Gakuin University Research advancement and management organization, Yokohama Kanagawa 236-8501, Japan \\ 4 Kurita Water Industries Ltd., Shimotsuga-gun Tochigi 329-0105, Japan \\ 5 College of Science and Engineering, Kanto Gakuin University, Yokohama Kanagawa 236-8501, Japan \\ * Corresponding author: e-mail: nakapa@outlook.jp
}

\begin{abstract}
High adhesion strength between Acrylonitrile Butadiene Styrene (ABS) plastic and plated metal has been conventionally obtained by chromic acid etching in manufacturing industry. However, in recent years, hexavalent chromium becomes the target as an environmental regulatory substances. Thus, the establishment of a chromium-free pretreatment method is expected. Electrolyzed sulfuric acid (ESA) is a unique oxidizer alternative to the chromic acid. Therefore, we have been trying to apply ESA to treat the surface of ABS plastic. Depending on the sulfuric acid concentration in ESA solution, modification effects such as changing the surface morphology and introducing the functional groups were different. The ESA in which the concentration of sulfuric acid is $75 \mathrm{wt} \%$ and $80 \mathrm{wt} \%$ can change ABS resin surface in quality to be hydrophilic from hydrophobic. Also, adhesion strength between plating metal film and the plastic was obtained maximum $1.2 \mathrm{kN} / \mathrm{m}$. Mechanism of high adhesion was anchor effect with cohesion failure. Therefore, this environmentally friendly surface modification method is expected in industrial use.
\end{abstract}

Key words: electrolyzed sulfuric acid, ABS plastic, adhesion strength

\section{INTRODUCTION}

ABS plastic is widely used, for example as parts of automobiles, because it is easy to be plated. Generaly, the surface of the plastic is hydrophobic, the surface must be changed to be hydrophilic by strong oxidizers to get high adhesion strength between metal plating film and the plastic. As the oxidizers, chromic acid and permanganic acid are used as an etching solution for plating pretreatment are strong oxidizer agents, but have stringent effluent standard and are harmful to the environment and humans[1,2]. Therefore, to substitute the above oxidizers, environmentally friendly methods for metal plating on plastic are researched [3-5].

Electrolyzed sulfuric acid (ESA), is obtained by the electrolysis of concentrated sulfuric acid, to generate the new oxidizer. ESA treatment is a unique technology for providing oxidizers including peroxodisulfuric acid $\left(\mathrm{H}_{2} \mathrm{~S}_{2} \mathrm{O}_{8}\right.$, as equation 1) and peroxomonosulfuric acid $\left(\mathrm{H}_{2} \mathrm{SO}_{5}\right.$, as equation 2), etc [6].

$$
\begin{aligned}
& 2 \mathrm{H}_{2} \mathrm{SO}_{4} \rightarrow \mathrm{H}_{2} \mathrm{~S}_{2} \mathrm{O}_{8}+\mathrm{H}_{2} \\
& \mathrm{H}_{2} \mathrm{~S}_{2} \mathrm{O}_{8}+\mathrm{H}_{2} \mathrm{O} \rightarrow \mathrm{H}_{2} \mathrm{SO}_{5}+\mathrm{H}_{2} \mathrm{SO}_{4}
\end{aligned}
$$

$\mathrm{H}_{2} \mathrm{~S}_{2} \mathrm{O}_{8}$ is adopted to remove photoresist or the residue of silicide metal in semiconductor manufacturing industry [7]. $\mathrm{H}_{2} \mathrm{~S}_{2} \mathrm{O}_{8}$ has two important merits: 1) 2.01 volt of oxidation-reduction potential, and 2) long lifetime [8,9]. $\mathrm{H}_{2} \mathrm{~S}_{2} \mathrm{O}_{8}$ can be generated by sulfuric acid electrolysis, then constant concentration maintained using diamond electrodes [10,11].

The present paper described the ESA technology as plating pretreatment for ABS plastic. We deduced adhesion mechanism of ESA treatment for plating on ABS plastic by FE-SEM and FT-IR.

\section{EXPERIMENTAL METHODS}

\subsection{Substrate}

In this experiment, commercially produced ABS plastics was used as the substrate. The product name was Toughace R EAR003 (Sumitomo Bakelite Co., Ltd. Japan).

\subsection{ESA solution}

The ESA solutions were prepared with different concentrated sulfuric acid; $70 \mathrm{wt} \%, 75 \mathrm{wt} \%$ and $80 \mathrm{wt} \%$. The electrolytic cell with diamond electrodes and without diaphragm were used to electrolyze the sulfuric acid. Generated $\mathrm{H}_{2} \mathrm{~S}_{2} \mathrm{O}_{8}$ concentration was about $10 \mathrm{~g} / \mathrm{dm}^{3}$ [12] The ESA solution was circulated between the electrolytic cell and treatment tank.

\subsection{Experiment procedure}

Table 1 shows the plating procedure for ABS plastic. Heat treatment was performed before ESA treatment to release tensile stress generated at the forming in $\mathrm{ABS}$ plastic. After ESA treatment, ABS plastic was rinsed in ultrasonic hot water at $60{ }^{\circ} \mathrm{C}$ for $10 \mathrm{~min}$ and immersed in alkaline solution. A conditioning agent improved the wettability of ABS surface and increased the adsorption amount of palladium catalyst adsorbed on ABS plastic, 
which is used to initiate electroless plating. Catalyzing step and accelerating step in plating procedure were treated twice to adsorb palladium onto the surface of ABS plastic steadily.

After the second accelerating treatment, ABS plastic was immersed to electroless Ni-P plating bath for $5 \mathrm{~min}$. The bath composition was the same one reported previously [4], used to deposit about a $0.2 \mu \mathrm{m}$ thick Ni-P plating film was on the surface, followed by electro deposited copper film (about $20 \mu \mathrm{m}$ thick) on the Ni-P film using a copper sulfate acid plating bath with the current density $3 \mathrm{~A} / \mathrm{dm}^{2}$ at room temperature. The copper sulfate acid plating bath contained copper sulfate $(0.3$ $\left.\mathrm{mol} / \mathrm{dm}^{3}\right)$ and sulfuric acid $\left(4.0 \mathrm{~mol} / \mathrm{dm}^{3}\right)$ and the Top Lucina SF series (Okuno Chemical Industries Co. Ltd, Japan) were used as the additives.

Table 1 Plating procedure

\begin{tabular}{|c|}
\hline Heat treatment, $75^{\circ} \mathrm{C}, 60 \mathrm{~min}$ \\
$\downarrow$ \\
\hline ESA treatment, $50{ }^{\circ} \mathrm{C}, 5-30 \mathrm{~min}$ \\
$\downarrow$ \\
\hline Ultrasonic cleaning, $60{ }^{\circ} \mathrm{C}, 10 \mathrm{~min}$ \\
\hline$\downarrow$ \\
\hline Alkaline treatment, $65^{\circ} \mathrm{C}, 3 \mathrm{~min}\left(\mathrm{NaOH} 50 \mathrm{~g} / \mathrm{dm}^{3}\right)$ \\
\hline$\nabla$ \\
\hline
\end{tabular}

Conditioning, $45^{\circ} \mathrm{C}, 2 \mathrm{~min}$

(CC-231 10 vol\%, ROHM and HAAS)

\begin{tabular}{|c|}
\hline$\nabla$ \\
\hline Catalyzing, $45{ }^{\circ} \mathrm{C}, 5 \mathrm{~min}\left(\mathrm{PdCl}_{2} 0.3 \mathrm{~g} / \mathrm{dm}^{3}\right)$ \\
\hline$\nabla$ \\
\hline $\begin{array}{l}\text { Accelerating, } 45^{\circ} \mathrm{C}, 1 \mathrm{~min} \\
\left(\mathrm{NaH}_{2} \mathrm{PO}_{2} \cdot \mathrm{H}_{2} \mathrm{O} 19.4 \mathrm{~g} / \mathrm{dm}^{3}\right)\end{array}$ \\
\hline$\nabla$ \\
\hline Catalyzing, $45{ }^{\circ} \mathrm{C}, 5 \mathrm{~min}\left(\mathrm{PdCl}_{2} 0.3 \mathrm{~g} / \mathrm{dm}^{3}\right)$ \\
\hline$\nabla$ \\
\hline $\begin{array}{l}\text { Accelerating, } 45^{\circ} \mathrm{C}, 1 \mathrm{~min} \\
\left(\mathrm{NaH}_{2} \mathrm{PO}_{2} \cdot \mathrm{H}_{2} \mathrm{O} 19.4 \mathrm{~g} / \mathrm{dm}^{3}\right)\end{array}$ \\
\hline$\nabla$ \\
\hline Electroless Ni-P plating, $0.2 \mu \mathrm{mt}$ \\
\hline$\nabla$ \\
\hline Heat treatment, $75^{\circ} \mathrm{C}, 60 \mathrm{~min}$ \\
\hline$\downarrow$ \\
\hline $\begin{array}{c}\text { Degreasing, } 40{ }^{\circ} \mathrm{C}, 5 \mathrm{~min} \\
\left(\text { Surfactant } 2.0 \mathrm{~g} / \mathrm{dm}^{3}, \mathrm{NaOH} 8.0 \mathrm{~g} / \mathrm{dm}^{3} \text {, }\right. \\
\text { Sodium citrate } 10.0 \mathrm{~g} / \mathrm{dm}^{3} \text { ) }\end{array}$ \\
\hline$\nabla$ \\
\hline Activating, R.T., $1 \mathrm{~min}\left(\mathrm{H}_{2} \mathrm{SO}_{4} 10\right.$ vol\%) \\
\hline$\nabla$ \\
\hline $\begin{array}{c}\text { Displacement prevention, } 40{ }^{\circ} \mathrm{C}, 30 \mathrm{~s} \\
\left(\mathrm{PdCl}_{2} 0.3 \mathrm{~g} / \mathrm{dm}^{3}\right)\end{array}$ \\
\hline$\nabla$ \\
\hline Electro $\mathrm{Cu}$ plating, $20 \mu \mathrm{mt}$ \\
\hline$\nabla$ \\
\hline Heat treatment, $75^{\circ} \mathrm{C}, 60 \mathrm{~min}$ \\
\hline
\end{tabular}

$\nabla:$ Water rinsing $\downarrow:$ No water rinsing

\subsection{Evaluation of adhesion strength}

The $90^{\circ}$ Peeling test is used to quantitatively evaluate the adhesion strength between the metal plating layer and
ABS plastic generally. In this evaluation, the copper plating films were cut into $10 \mathrm{~mm}$ width for the peeling tests. The universal testing machine (EZ-Test, Shimadzu Co. Ltd, Japan) was used.

2.5 Evaluation of surface morphologies and functional groups

Before and after the ESA treatment, the surface morphologies were observed by FE-SEM (Field Emission Scanning Electron Microscopy, JSM-7001F, JEOL Co. Ltd, Japan).

Surface functional groups were analyzed using FT-IR (Fourier Transform Infrared Spectroscopy, FT/IR4100, JASCO Co., Japan) fitted with ATR diamond prism (PKS-D 470 with ATR PRO450-S, JASCO Co., Japan). The measurement range was from $4000 \mathrm{~cm}^{-1}$ to $800 \mathrm{~cm}^{-1}$.

\section{RESULTS AND DISCUSSION}

3.1 Influence of adhesion strength by ESA

As blisters occurred after electrolytic copper plating on the untreated substrate and the substitutes treated by ESA at $70 \mathrm{wt} \%, 5-10$ minute, their peeling tests could not be evaluated.

Fig.1 shows the influence of ESA treatment time and sulfuric acid concentration to the adhesion strength. For the $70 \mathrm{wt} \%$ ESA concentration, the adhesion strengths were under $0.1 \mathrm{kN} / \mathrm{m}$. It is suggested that ESA $70 \mathrm{wt} \%$ is insufficient to modify the surface of ABS plastic for plating metal films. For the $75 \mathrm{wt} \%$ ESA concentration, the adhesion strengths increased in proportion to treatment time, and the maximum was over $1.2 \mathrm{kN} / \mathrm{m}$. On the other hand, for the $80 \mathrm{wt} \%$ ESA condition, the adhesion strengths decreased in inverse proportion to treatment time. It is found that the slight $5 \mathrm{wt} \%$ different in sulfuric acid concentration influenced the adhesion strength greatly.

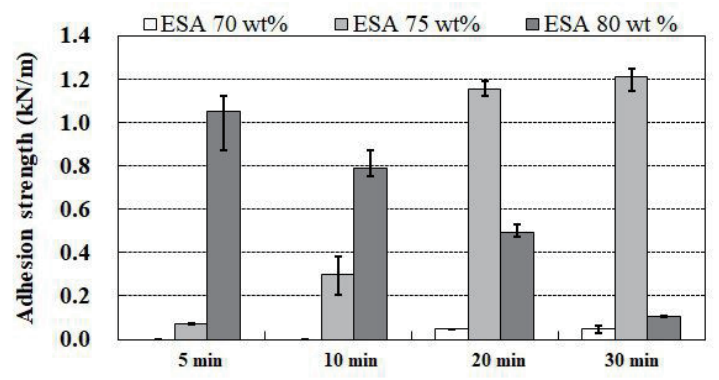

Fig.1 Effect of ESA treatment on the adhesion strength of deposited copper film on the ABS plastics.

\subsection{Observation of surface morphology}

Fig. 2 shows FE-SEM image of the untreated ABS plastic. The untreated ABS plastic has a sea-island structure in which Acrylonitrile-Styrene (AS) phase forms the continuous ocean and Polybutadiene (PB) rubber phase is serves as the island [13].

Fig. 3 shows FE-SEM images of ABS plastics after the ESA treatment. The surface morphology of $70 \mathrm{wt} \%$ ESA treatment was similar to the untreated ABS plastic (Fig.2). Even though the treatment times were extended, the number of dimples were present at any condition. In contrast, there were many dimples on all the surface of ABS plastic at the treatments of $75 \mathrm{wt} \%$ and $80 \mathrm{wt} \%$ ESA. Reference 4 claimed that the observed dimples occurred by butadiene dissolution [4]. The strength of ESA 
treatment increases from the upper left to the lower right in Fig.3.

If enough adhesion strength is over $0.7 \mathrm{kN} / \mathrm{m}$, the range from $75 \mathrm{wt} \%$ ESA, $20 \mathrm{~min}$ or $80 \mathrm{wt} \%$ ESA, $10 \mathrm{~min}$ are the suitable treatment condition as shown in Fig.1. We assume that the dimples which are generated by dissolving PB function as the anchors between the metal film and ABS plastic and improve the adhesion strength. From the viewpoint, as there are few dimples at $75 \mathrm{wt} \% \mathrm{ESA}$, or less $10 \mathrm{~min}$, there treatment conditions are not enough. On the other hand, at $80 \mathrm{wt} \%$ ESA. $20 \mathrm{~min}$ and over the number of dimples are almost same. So we guess that ESA excessive treatment swells the surface layer of ABS plastic and weakens the strength.

\subsection{Surface analysis by FT-IR}

Fig.4, Fig.5 and Fig.6 shows the results of the FT-IR measurements on ABS plastic surface before and after 70 wt $\%$ ESA, $75 \mathrm{wt} \%$ ESA, and $80 \mathrm{wt} \%$ ESA treatment respectively. On the ABS treated with $70 \mathrm{wt} \%$ ESA, the spectra of treated ABS were similar to the untreated ABS. The surfaces treated by $70 \mathrm{wt} \%$ ESA did not have noticeable variation in functional groups compared to the untreated ABS plastic.

After $75 \mathrm{wt} \%$ ESA treatment, three adsorption bands at $1120 \mathrm{~cm}^{-1}, 1540 \mathrm{~cm}^{-1}$ and $3300 \mathrm{~cm}^{-1}$ became apparent. The $1120 \mathrm{~cm}^{-1}$ shoulder band is sulfonyl group $\left(-\mathrm{SO}_{2}\right)$. The weak band at $1540 \mathrm{~cm}^{-1}$ is carboxylate group $\left(\mathrm{COO}^{-}\right)$ $[14,15]$. The broad band at $3300 \mathrm{~cm}^{-1}$ was represented as a hydroxyl group $(-\mathrm{OH})$ [3]. As mentioned above, the surface state of ABS plastic was converted from hydrophobic to hydrophilic by $75 \mathrm{wt} \%$ ESA treatment.
With the $80 \mathrm{wt} \%$ ESA treatment, absorption peaks at $1200 \mathrm{~cm}^{-1}\left(-\mathrm{SO}_{3}\right), 1700 \mathrm{~cm}^{-1}(\mathrm{C}=\mathrm{O})$ and at $3300 \mathrm{~cm}^{-1}$ $(-\mathrm{OH})$ were increased with increase of treatment time [16] On the other hand, absorption at $911 \mathrm{~cm}^{-1}$ and $967 \mathrm{~cm}^{-1}$ $(\mathrm{C}=\mathrm{C}), 1450 \mathrm{~cm}^{-1}$ and $1500 \mathrm{~cm}^{-1}$ (aromatic $\mathrm{C}=\mathrm{C}$ ) 2200 $\mathrm{cm}^{-1}(\mathrm{C} \equiv \mathrm{N}), 2920 \mathrm{~cm}^{-1}(\mathrm{C}-\mathrm{H}), 3030 \mathrm{~cm}^{-1}$ (aromatic C-H) were decreased with treatment time $[17,18]$.

These results suggested the AS matrix phase as well as butadiene were degraded by $80 \mathrm{wt} \%$ ESA solution. Moreover, it was suggested that the sulfonation and carbonylation from absorption at $1200 \mathrm{~cm}^{-1}\left(-\mathrm{SO}_{3}\right)$ and $1700 \mathrm{~cm}^{-1}(\mathrm{C}=\mathrm{O})$ were carried out on the ABS plastic. As the processing time increased, the surface state was found to be deteriorated by increasing and decreasing of each functional groups.

Therefore, 70 wt \% ESA treatment had insufficient oxidation ability, the $75 \mathrm{wt} \%$ ESA treatment caused mild oxidation on the ABS plastic, and that the $80 \mathrm{wt} \%$ ESA treatment oxidation was strong and each component of ABS plastic decomposed by excess treatment. Thus, the change of functional groups was different by ESA concentration.

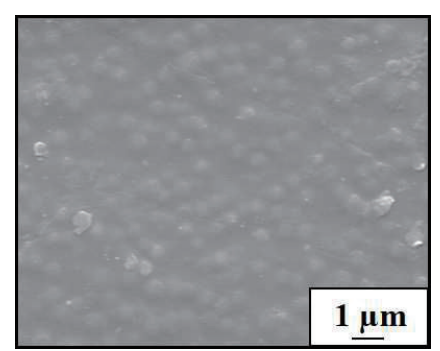

Fig.2 FE-SEM image of the untreated ABS plastic surface.

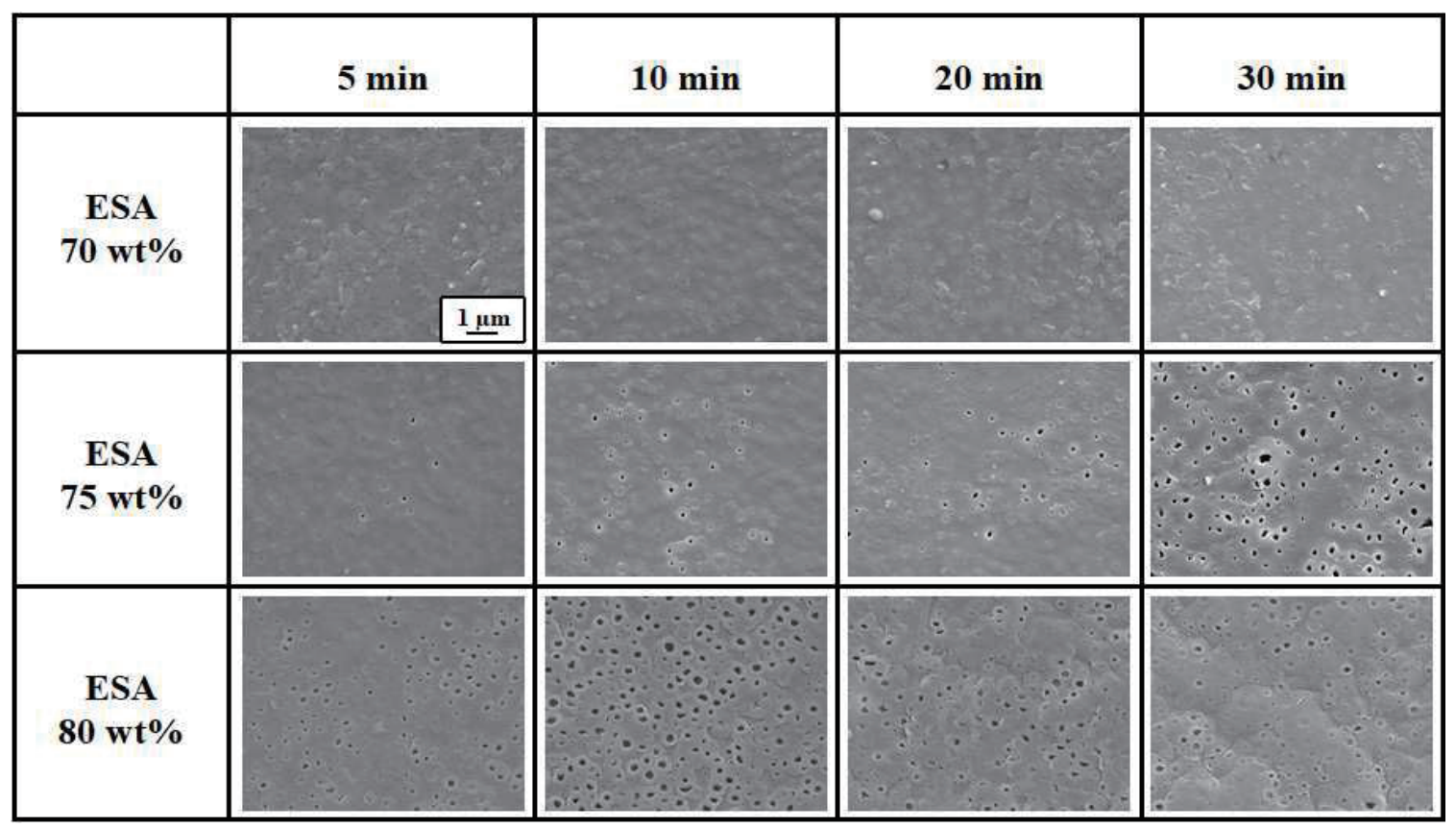

Fig. 3 FE-SEM images of the ABS plastic surface modified by various ESA treatment. 


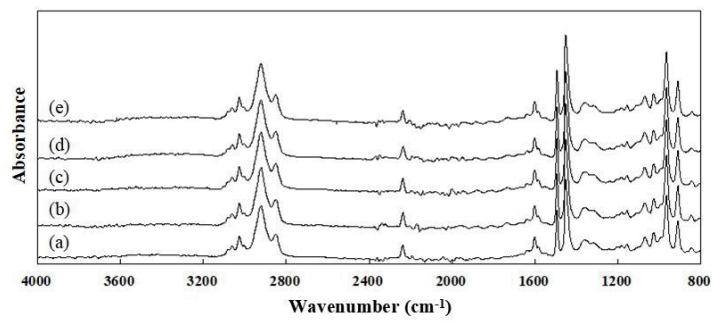

Fig.4 FT-IR spectra of ABS plastic treated by $70 \mathrm{wt} \%$ ESA solution.

(a)Untreated, (b)5 min, (c)10 min, (d)20 min, (e)30 min

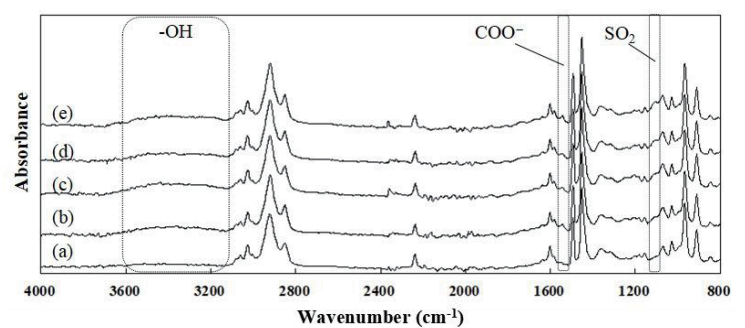

Fig.5 FT-IR spectra of ABS plastic treated by $75 \mathrm{wt} \%$ ESA solution.

(a)Untreated, (b)5 min, (c)10 min, (d)20 min, (e)30 min

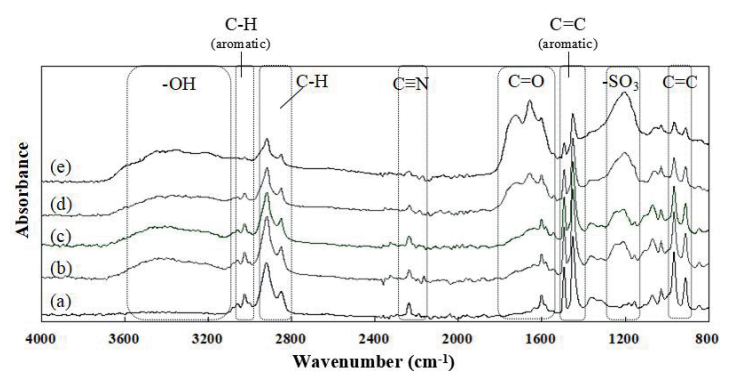

Fig.6 FT-IR spectra of ABS plastic treated by $80 \mathrm{wt} \%$ ESA solution.

(a)Untreated, (b)5 min, (c)10 min, (d)20 min, (e)30 min

\subsection{Adhesion mechanism}

Fig.7 shows FE-SEM image of ABS plastic after the peeling test. Fig. 8 shows schematic diagram of adhesion mechanism by ESA treatment. ESA treatment at $70 \mathrm{wt} \%$, it showed smooth surface. It was possible to deposit electroless plating (Fig.7-a). However, the adhesion strength is low because surface functional groups were not converted. Therefore, interface delamination occurred between metal plating and ABS plastic (Fig.8-a) [19].

For the $75 \mathrm{wt} \%$ ESA of short time treatment (5-10 min), there were many dimples but low adhesion states. At long treatment time (20-30 min), the dimples from dissolution butadiene caused a physical anchor effect (Fig. 7-b). It was suggested that metal film was deposit from catalyst penetrated layer and modification layer [20-21]. In this reasons, high adhesion strength was obtained by powerful anchor effect with cohesion failure (Fig.8-b).

On 80 wt $\%$ ESA, many dimples and small cracks (Fig. 7-c) were observed. The ABS plastic surface was converted and existed weak boundary layer by excessive treatment (Fig. 8-c) [22]. Thus, the adhesion strength was greatly reduced with increase treatment time.

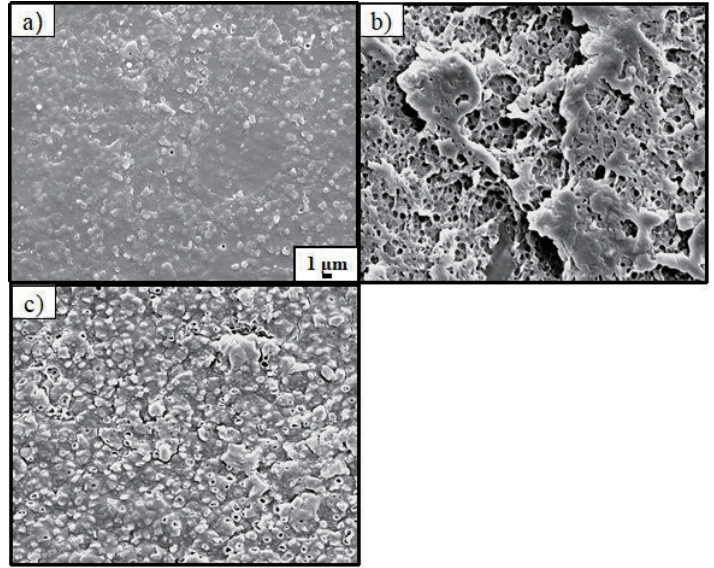

Fig.7 Surface appearance of ABS resin after peeling test.

a) ESA $70 \mathrm{wt} \% 30 \mathrm{~min}$

b) ESA $75 \mathrm{wt} \% 30 \mathrm{~min}$

c) ESA $80 \mathrm{wt} \% 30 \mathrm{~min}$

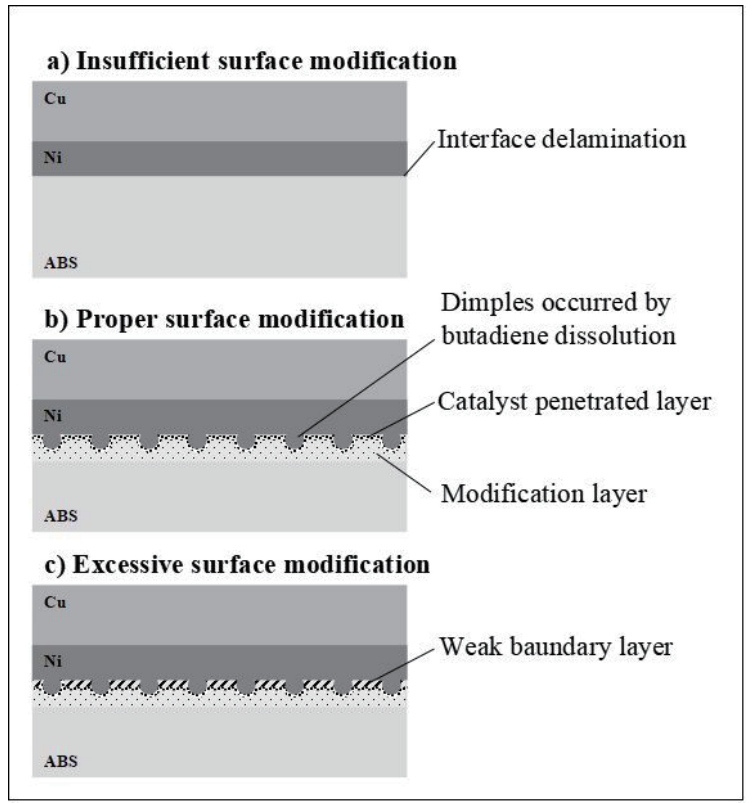

Fig.8 Schematic diagram of mechanism for phenomenon of adhesion.

\section{CONCLUSION}

The surface modification performance of ESA treatment was varied greatly due to the difference sulfuric acid concentration in the range of 70 to $80 \mathrm{wt} \%$. As the results, high adhesion strength of plating on the ABS plastic was achieved by optimization of the ESA concentration and treatment time. Then, it was suggested that improving adhesion strength was affected by anchor effect. Therefore, this environmentally friendly surface modification process is expected to be applied to plating on plastic in the future.

\section{REFERENCES}

[1] K. Kita, J. surf finish. Soc Japan, 64, 622-627(2013).

[2] L. A. C. Teixeira and M. C. Santini, Journal of Materials Processing Technology, 170, 37-41(2005).

[3] K. Tashiro, M. Sugimoto, K. Watanabe, T. Besshyo and H. Honma, Journal of The Japan Institute of 
Electronics Packaging, 8, 133-130(2005).

[4] Y. Nishimura, S. Suzuki, K. Tashiro, Y. Umeda and T. Yamashita, Materials science and technology, 50, 146-151(2013).

[5] H. Song, J. M. Choi and T. W. Kim, Transactions on Electrical and Electronic Materials, 14, 133-138(2013).

[6] H. Hori, R. Manita, K. Yamamoto, S. Kutsuna, M. Kato, Journal of Photochemistry and Photobiology A, 322, 167-173(2017).

[7] T. Nagai, J. surf finish. Soc Japan, 67, 421-426(2016).

[8] Y. Ogawa, M. Uchida, T. Otsu, T. Nagai and H.Morita, Solid State Phenomena, 219, 101-104(2015).

[9] J. H. Ahn, P. D. Kim, S. C. Hwang, J. Seo, S. Lee, Y. Ogawa, J. Ida, Y. Sasaki, T. Nagai and T.Otsu, ECS Trans, 77, 207-212(2017).

[10] F. Hippauf, S. Dorfler, R. Zedlitz, A. Vater and S. Kaskel, Electrochimica Acta, 147, 589-595(2014).

[11] H. Song, L. Yan, J. Jiang, J. Ma, Z. Zhang, J. Zhang, P. Liu and T. Yang, Water Research, 128, 393-401(2018).

[12] T. Nagai, Y. Yamamoto and Y. Sakamoto, Materials science and technology, 53, 64-67(2016).

[13] P. Song, Z. Cao, S. Fu, Z. Fang, Q. Wu and J. Ye, Thermochimica Acta, 518, 59-65(2011).

[14] T. Takahashi, T. Nagano, K. Wada, Y. Suzuki, H. Tagai and S. Kimura J. metal finish. Soc Japan, 23, 700-708(1972).

[15] F. X. Perrin, V. Nguyen and J. L. Vernet, Journal of Sol-Gel Science and Technology, 28, 205-215(2003).

[16] H. Nawafue, Y. Matsumoto, K. Kugo, . Mizumoto, M. Seita, M. Imanari, The Journal of Japan Insitute for Interconnecting and Packaging Electronic Circuit, 10, 457-461(1995).

[17] N. Teramae and T. Ishioka, Journal of the Japan Society of Color Material, 69, 784-793(1996).

[18] L. M. Cacho, J. J. P. Bueno, Y. M. Vong, G. Stremsdoerfer, F. J. E. Beltran, J. M. Vega, Journal of Coatings Technology and Research, 12, 313-323(2015).

[19] T. Morikawa, T. Nakade, M. Yokoi, J. surffinish. Soc Japan, 58, 267-274(2007).

[20] T. Bessho, K. Tashiro, M. Sugimoto, H. Honma, Journal of The Japan Insitute of Electronics Packaging, 9, 472-478(2006).

[21] Y. Umeda, T. Nomura, H. Nakagawa, Y. Nakabayashi, K. Tashiro, H. Honma, O. Takai, Journal of The Japan Insitute of Electronics Packaging, 19, 492-500(2016).

[22] Y. Ohkubo, K. Ishihara, H. Sato, K. Endo, K. Yamamura, J. surffinish. Soc Japan, 67, 551-556(2016).

(Received June 20, 2018; Accepted September 10, 2018; Published Online December 1, 2018) 